\title{
Tethered cord syndrome and occult spinal dysraphism
}

\author{
Daryl E. Warder, M.D., Ph.D. \\ Department of Surgery, Division of Neurosurgery, The University of Texas Medical Branch, \\ Galveston, Texas
}

\begin{abstract}
Tethered cord syndrome is a progressive form of neurological deterioration that results from spinal cord tethering by various dysraphic spinal abnormalities. The syndrome, treatments, outcomes, and current controversies are reviewed.
\end{abstract}

KEY WORDS - tethered cord syndrome - occult spinal dysraphism

Progressive neurological deterioration localized to the lower spinal cord resulting from traction on the conus medullaris has been termed TCS and has been described in children ${ }^{23,24}$ and adults. ${ }^{57,61}$ This syndrome of neurological deterioration was described and treated in 1891 by Jones. ${ }^{29}$ It was again described in $1918,{ }^{5}$ and the recommendation for surgical intervention was made. It was rediscovered in the mid-20th century..$^{19,27,44,45}$ In its classic form, TCS involves traction on a low-lying conus medullaris $;{ }^{17,57}$ however, TCS has also been described in the setting of a conus medullaris in the "normal" position. ${ }^{69,70}$ Features associated with the syndrome include the dysraphic spinal elements, cutaneous stigmata of OSD, vertebral anomalies, orthopedic abnormalities (scoliosis and extremity abnormalities), neurological deterioration at the level of the lower spinal cord including bowel and bladder dysfunction, and anorectal malformations. ${ }^{12,71}$

Mechanical traction on the spinal cord may be a cause of progressive symptoms. ${ }^{48}$ Yamada, et al., ${ }^{73}$ have proposed that symptoms appear after hypoxic damage within the conus medullaris of patients with TCS. Blood flow improvement has been noted after the spinal cord has been surgically untethered. ${ }^{63}$ Retethering of the spinal cord may occur in patients with OSD who have previously undergone an untethering procedure and may also occur in patients with previously repaired myelomeningoceles. ${ }^{48}$

Spinal dysraphism is a term that refers to all forms of developmental abnormalities occurring in the midline of the back-from the skin externally to the vertebral bodies internally. ${ }^{26}$ Although the true incidence of spinal dys-

Abbreviations used in this paper: $\mathrm{CT}=$ computerized tomography; $\mathrm{MR}=$ magnetic resonance; $\mathrm{OSD}=$ occult spinal dysraphism; $\mathrm{SCM}=$ split cord malformation; $\mathrm{TCS}=$ tethered cord syndrome . raphism is unknown, authors of some studies have estimated an incidence of 0.05 to 0.25 per 1000 births. ${ }^{33,67}$ These abnormalities usually involve the lumbosacral spine, although lesions in the cervical and thoracic region do occur. Spinal dysraphism, which may result in a tethered spinal cord, exists in an open form, spina bifida aperta, and in a closed form, spina bifida occulta. The most common expression of spina bifida aperta is the myelomeningocele. Common forms of spina bifida occulta include the lipomyelomeningocele and diastematomyelia.

The same term, spina bifida occulta, when it refers to a benign bone cleft in the L-5 or S-1 spinous process that occurs in approximately $17 \%$ of the total population and $30 \%$ of normal individuals aged 1 to 10 years, ${ }^{4,40}$ does not imply an association with a tethered spinal cord or TCS.

\section{EMBRYOLOGICAL FEATURES OF SPINAL DYSRAPHISM}

Human intrauterine development is divided into the embryonic and fetal periods. ${ }^{16,43}$ The embryonic period includes the first 50 to 62 days postconception, ${ }^{16}$ and has itself been divided into 23 stages. ${ }^{68}$ Each stage encompasses approximately 2 to 3 days. The fetal period includes the subsequent 7 months of gestation. ${ }^{16}$ Stages 8 through 14 (Days 18-32) are of particular importance with respect to the development of the central nervous system. During these stages the three major steps of the development of the central nervous system occur. These steps include neurulation, canalization of the tail bud, and regression. Neurulation, the process by which the neural tube is formed, occurs during stages 8 through 20 (Days 18-48). During this process, the flat neural plate folds on itself into a neural tube which is covered by a continuous layer of cutaneous ectoderm. ${ }^{16}$ The closure of the neural tube begins in 


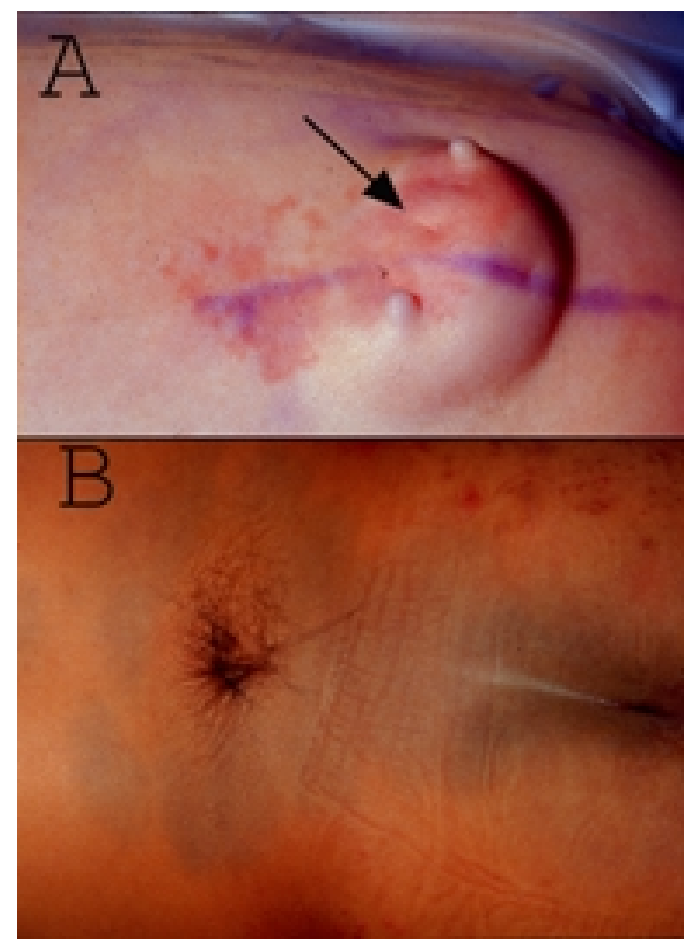

Fig. 1. Photographs showing cutaneous stigmata of OSD. A: One of three dermal sinuses (arrow). Also present are a subcutaneous lipoma and cutaneous hemangioma. B: A hairy patch of the lumbosacral spine is displayed.

the upper cervical region and then extends caudally and cephalically. During stage 12, the caudal portion of the neural tube closes at the level L-1 or L-2. ${ }^{16}$ Neurulation gives rise to the spinal cord only down to the lumbar spine region. The spinal cord caudal to this is formed by the process of canalization. Errors during neurulation may lead to various congenital malformations such as myelomeningocele, meningocele, lipomyelomeningocele, SCMs, the dermal sinus, and intraspinal tumors such as dermoids and epidermoids. With the completion of neurulation, the neural tube is totally covered by cutaneous ectoderm. ${ }^{16}$

The tail bud forms after completion of neurulation. The formation of the neural tube caudal to that formed during neurulation occurs by canalization of the tail bud, which occurs during stages 13 through 20 (Days 28-48). ${ }^{16}$ This process consists of the development of vacuoles within the tail bud, then coalescence of these vacuoles to form the canal, which then connects with the rostral neural tube formed during neurulation. Abnormalities that develop during canalization of the tail bud can give rise to the thick terminal filum, terminal myelocystocele, and lipomyelomeningocele.

The terminal filum and cauda equina are formed from the caudal portion of the neural tube by regression. The ventriculus terminalis marks the level of the future conus medullaris and is a dilation of the central canal that can be identified at stages 18 through 20 (Days 43-48) at which time it lies at the coccygeal level. The tip of the vertebral coccygeal segments contains an epidermal cell rest, the coccygeal medullary vestige. The terminal filum is formed when the caudal neural tube regresses between the ventriculus terminalis and the coccygeal medullary vestige and is first present at stage 23 (Day 52). During the fetal period, the vertebral canal grows faster than the neural tube, resulting in the "ascent" of the spinal cord. At the time of birth, the conus medullaris has reached the L2-3 space in the majority of individuals, ${ }^{3}$ and it has reached the adult level by age 3 months.

\section{ASSOCIATED CLINICAL FEATURES OF SPINAL DYSRAPHISM}

\section{Cutaneous Stigmata}

The cutaneous changes associated with OSD and TCS include the midline lumbosacral cutaneous hemangiomas (Figs. 1A and 2B), lumbosacral hypertrichosis (Fig. 1B), the lumbosacral dermal sinus (Fig. 1A), the midline lumbosacral subcutaneous lipoma (Figs. 1A and 2), and the lumbosacral skin appendage (Fig. 2A). ${ }^{27}$ The cutaneous stigmata of OSD are present in approximately $50 \%{ }^{70}$ of patients who present with TCS.

\section{Neurological Orthopedic Changes}

Progressive neurological changes including radicular pain, weakness, asymmetric hyporeflexia, spasticity, sensory changes, and bowel/bladder dysfunction occur in approximately $75 \%$ of patients presenting with TCS. ${ }^{48,70}$ Some authors have divided the neurological symptoms into upper motor neuron and lower motor neuron symptoms ${ }^{11}$ and consider that the lower motor neuron symp-

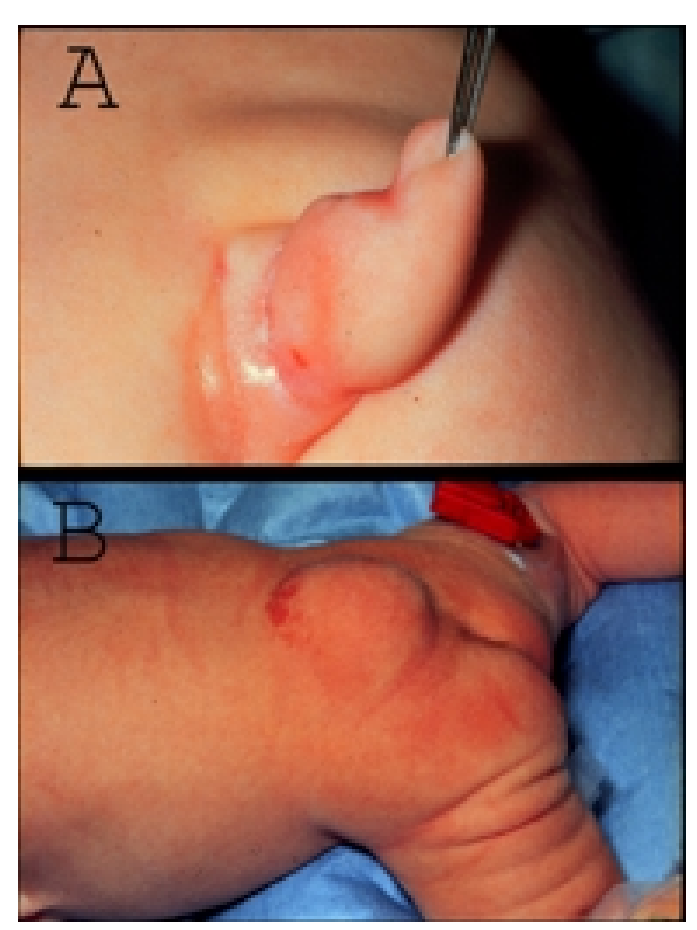

Fig. 2. Photographs showing cutaneous stigmata of OSD. A: A skin tag that resembles a tail and a subcutaneous lipoma are displayed. B: A subcutaneous lipoma and a cutaneous hemangioma are shown. 


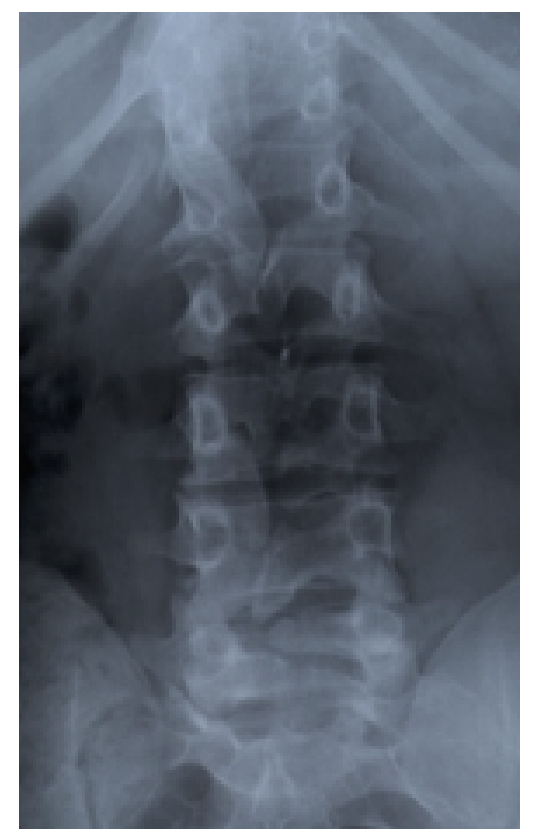

Fig. 3. A plain anteroposterior x-ray film of the lumbosacral spine revealing typical, widespread posterior fusion defects of the laminae.

toms may be due to local compression of the cord, nerve root dysgenesis, or local nerve root damage but may not be related to tethering. The upper motor neuron symptoms, however, are believed to result from the ischemic damage to the neural tissue caused by tethering. ${ }^{11}$

The neuroorthopedic syndrome ${ }^{21,26,41}$ includes foot deformities, limb-length abnormalities, muscular atrophy of the legs, gait disturbance, limb pain, and scoliosis. Approximately $75 \%$ of patients with TCS present with orthopedic anomalies. ${ }^{48}$

\section{Vertebral Anomalies}

Bone anomalies found in patients with TCS include bifid vertebrae, laminar defects (Fig. 3), hemivertebrae, sacral aplasia, sacral agenesis and multiple segmentation errors ${ }^{70}$ and may be found in approximately $95 \%$ of patients with $\mathrm{TCS}^{70}$ The bifid spinous process at L-5 or S-1, occurring in $30 \%$ of the normal population of children aged 1 to 10 years, itself is not a pathological problem. ${ }^{4}$

\section{Anorectal Anomalies}

Occult spinal dysraphism has been found to be associated with various anorectal and urogenital malformations including cloacal exstrophy, imperforate anus; vertebral defects, anal atresia, tracheoesophageal fistula, radial limb, and renal dysplasia; and bladder exstrophy. ${ }^{12,71}$ Approximately 10 to $50 \%$ of the patients with anorectal anomalies will also have an element of OSD. ${ }^{12,71}$

\section{OCCULT DYSRAPHIC ELEMENTS}

Intraspinal anomalies common to OSD include the lipomyelomeningocele, the dermal sinus, diastematomyelia, the tight terminal filum, the neurenteric cyst, the terminal myelocystocele, and meningocele manqué.

\section{SPECIFIC DYSRAPHIC ELEMENTS}

\section{Lipomyelomeningocele/Spinal Lipoma/Fatty Filum}

Fatty accumulations within the spinal cord represent $70 \%$ of the lesions associated with tethering ${ }^{55}$ and take three different forms. The lipomyelomeningocele is a subcutaneous lipoma within the spinal cord that extends through a defect of the lumbosacral fascia, lamina, dura, and pia into a low-lying spinal cord. ${ }^{25}$ It is the most common form of spinal lipoma. Patients with these lesions usually come to clinical attention within the first few months to years of life. ${ }^{52} \mathrm{~A}$ subset of the lipomyelomeningocele is the lipoma of the conus medullaris.

The intradural lipoma (spinal cord lipoma) is a rare intramedullary lesion that is usually found within the thoracic spinal cord. ${ }^{1}$ It is not associated with cutaneous or bone anomalies and often presents with symptoms of spinal cord compression. ${ }^{1}$

The fatty filum involves fatty infiltration the whole length or part of the terminal filum. The fat within the short, thick filum is discernible by unenhanced CT or MR imaging. ${ }^{46}$ The occurrence of incidental fat within the terminal filum in the normal adult population has been estimated to be $3.7 \%$ in cadaveric studies ${ }^{22}$ and 1.5 to $5 \%$ in MR imaging studies. ${ }^{6,72}$

Lipomyelomeningoceles may be diagnosed by the associated subcutaneous lumbosacral mass that is found in approximately $90 \%$ of patients ${ }^{48}$ or by sagittal MR imaging (Fig. 4) or ultrasonography studies. ${ }^{48}$ For those who come to medical attention before the age of 1 year, $59 \%$ of patients with the lipomyelomeningocele or fatty filum are asymptomatic whereas $41 \%$ are symptomatic. Of those patients with symptoms in one study, $60 \%$ presented with urological symptoms and 58\% with neurological symptoms, whereas $58 \%$ presented with orthopedic abnormalities (extremity abnormalities and scoliosis). ${ }^{7}$ Of patients presenting with motor deficits, 50 to $70 \%$ do not experience improvement after surgery. ${ }^{32,60}$ Surgical intervention in the symptomatic patient has been advocated by many

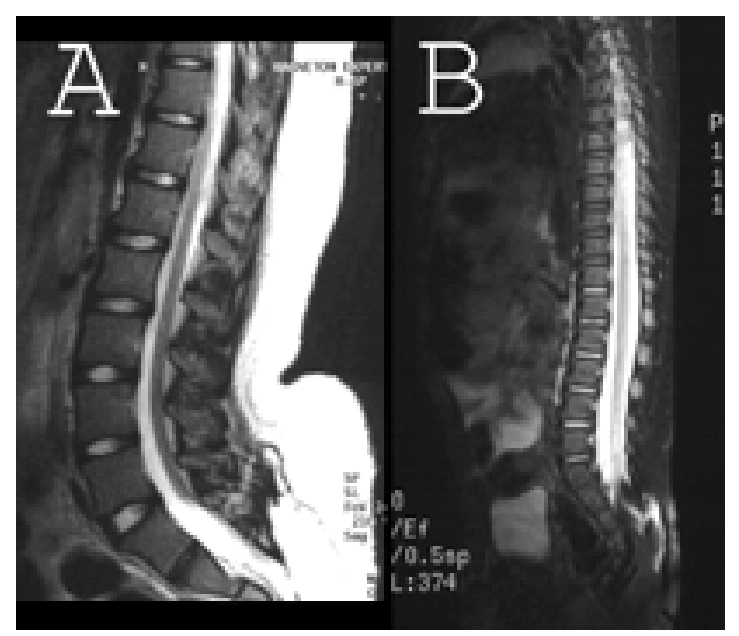

Fig. 4. Sagittal MR images demonstrating a lipomyelomeningocele. A: The spinal cord extends to the level of the sacrum. An associated superficial subcutaneous lipoma is discernible. B: The spinal cord extends to the level of the sacrum. A syrinx is present. 
authors to prevent further decline in the neurological status. ${ }^{7,33}$ A few authors believe that some of the lower motor neuron symptoms and orthopedic symptoms cannot be prevented by surgery. ${ }^{11}$

The operation for lipomyelomeningoceles has been significantly advanced by the use of the carbon dioxide laser and the ultrasonic aspirator. ${ }^{7,52}$ Intraoperative monitoring of nerve roots may be useful to distinguish those that are functional from those that are not. ${ }^{74}$ Once the spinal cord has been untethered, closure and enlargement of the dura with a graft material has been recommended. ${ }^{52,74}$ In one study $^{7}$ of those patients younger than 1 year of age who underwent an untethering procedure for lipomyelomeningocele or fatty filum and who presented with motor, urological, or orthopedic symptoms, 39\% improved, 58\% stabilized, and $3 \%$ worsened as a result of surgical intervention. $^{7}$

Surgical intervention for the lipoma of the filum in the symptomatic or asymptomatic patient has been well described and is well tolerated. ${ }^{48,74}$ In the symptomatic group, long-term follow-up review has demonstrated improvement or resolution of the presenting neurological or orthopedic abnormalities in $42.5 \%$ of patients, as well as stabilization of symptoms in $57.5 \% .^{48}$ In the asymptomatic group, the great majority of patients remain asymptomatic in the long term and suffer no neurological worsening as a result of the operation. ${ }^{48,74}$

Surgical intervention for the asymptomatic lipoma of the conus medullaris has been an area of controversy, ${ }^{11,48,74}$ primarily because of the paucity of studies in which the natural history of this disorder is detailed. Many authors have advocated the use of early prophylactic untethering to prevent deterioration, ${ }^{7,48}$ noting that asymptomatic patients rarely became symptomatic after the surgical procedure $^{32}$ and that a minority of symptomatic patients experienced reversal of their preoperative deficits. ${ }^{7,48}$ Other authors have maintained that, in their series of patients, prophylactic untethering may not prevent some deterioration, and, because the natural history of the asymptomatic lipoma of the conus medullaris is not clearly known, prophylactic untethering may not be warranted. ${ }^{74} \mathrm{~A}$ recent prospective study in which the authors examined the influence of surgery on the appearance of upper motor

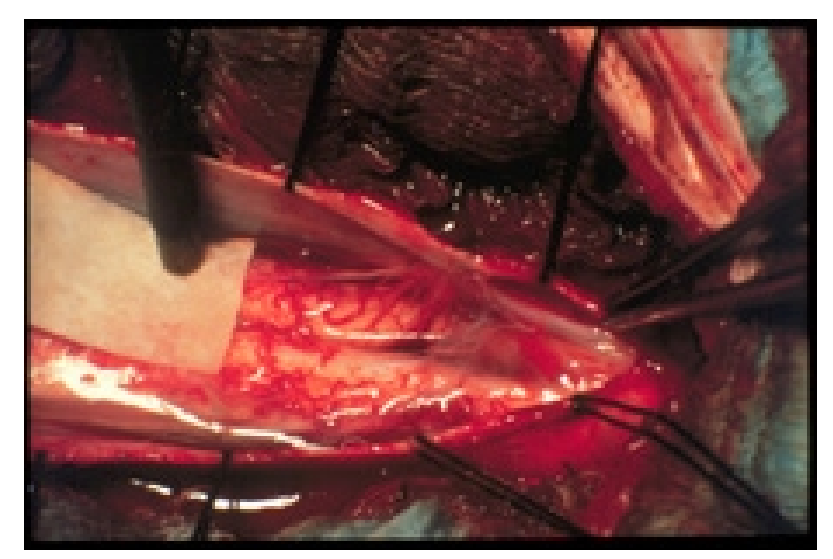

Fig. 5. Intraoperative photograph showing a diastematomyelia (SCM). neuron signs in newborns with a tethered spinal cord (of various causes $)^{11}$ included 22 consecutive patients, 17 of whom had a lipomyelomeningocele. In approximately $29 \%$ of the patients with a lipomyelomeningocele, upper motor neuron signs were present at birth, and $60 \%$ of the asymptomatic patients with a lipomyelomeningocele developed upper motor neuron signs over a short period of 2 to 24 months postbirth. Approximately $70 \%$ of the patients with a lipomyelomeningocele in this prospective study underwent untethering of the spinal cord because of either the presence of upper motor neuron signs at birth or the development of those signs during follow up. ${ }^{10,11}$

The majority of authors ${ }^{7,32,48,52}$ propose early prophylactic untethering in patients with asymptomatic lipoma of the conus medullaris because of the low rate of neurological worsening $(3-4 \%)$ resulting from the operation and because of the better neurological outcome at follow up of the asymptomatic patients as compared with that of symptomatic patients.

\section{Diastematomyelia (SCM)}

Diastematomyelia, also referred to as SCM, refers to the splitting of the spinal cord, conus medullaris, or terminal filum in the sagittal plane into two not necessarily equal halves. ${ }^{26,56} \mathrm{~A}$ united theory of SCMs describes a Type I malformation as a split cord residing in a common dural tube and a Type II malformation as a split cord divided by a bone spur with each hemicord residing in a separate dural tube. ${ }^{56} \mathrm{~A}$ thick cutaneous hairy patch usually overlies the region of the diastematomyelia. ${ }^{56,59}$ Diastematomyelia may account for up to $25 \%$ of OSD cases. ${ }^{2}$ Bone anomalies are present in $85 \%$ of cases, and scoliosis is present in $50 \%$ of cases of diastematomyelia. ${ }^{48}$ In $91 \%$ of cases, the two hemicords reform a single cord below the site of division. ${ }^{48}$ In $50 \%$ of cases, the hemicords are contained within a single dural tube (Type I malformation; Fig. 5) without a midline bone spur. ${ }^{48,56}$ Tethering may occur as a result of dorsal tethering bands between the hemicords and dura or from a thickened terminal filum. ${ }^{54}$ In the other $50 \%$ of cases, a median septum divides the hemicords, which are contained within separate dural tubes (Type II malformation). ${ }^{48,56}$ The median septum lies external to both dural tubes. ${ }^{48,56}$ Axial CT or CT myelography, or MR imaging (Fig. 6) is useful in demonstrating the hemicords and median septum. ${ }^{48}$ Surgical intervention may involve resecting the median septum and dividing a thickened filum and dorsal tethering bands. ${ }^{48,56}$ Andar, et al., ${ }^{2}$ have suggested that, although surgical intervention in patients with diastematomyelia may stabilize progressive neurological and urological symptoms and may prevent the onset of neurological and urological deterioration, it may not affect the emergence of the neuroorthopedic syndrome $^{21}$ of limb-length asymmetry and foot deformities.

\section{The Dermal Sinus}

Dermal sinus tracts appear as midline dimples in the lumbosacral region ${ }^{26}$ and may extend from the skin surface to the dura, subarachnoid space or the spinal cord, ${ }^{48}$ thereby causing tethering. The sinus tracts may serve as a pathway for infection and may present as meningitis. ${ }^{48}$ The extraspinal course of the dermal sinus may be visualized by CT or MR imaging whereas the intraspinal course 


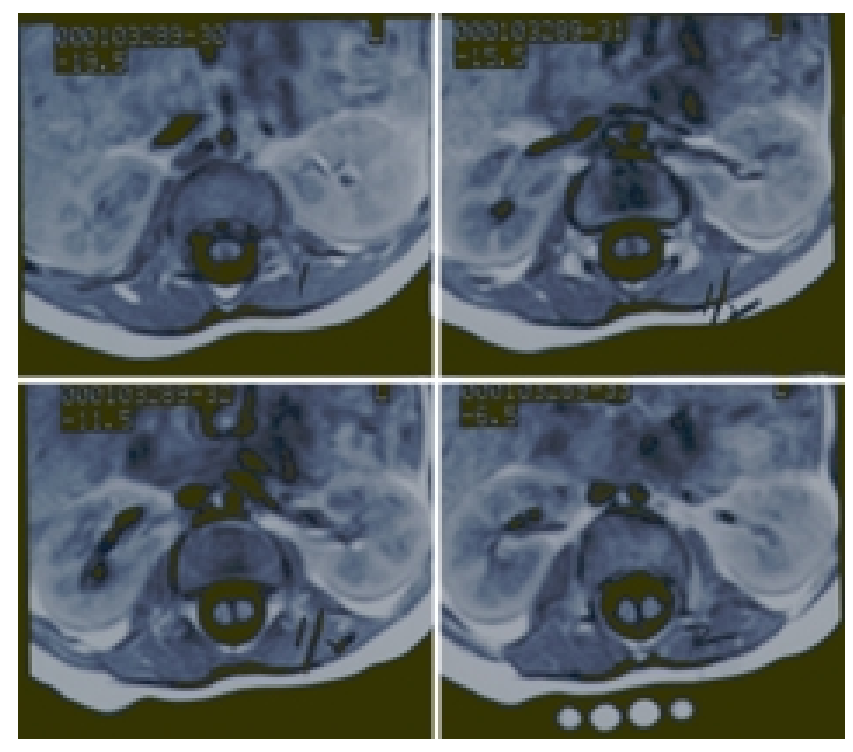

Fig. 6. Axial MR images revealing a split spinal cord (diastematomyelia). The images are displayed in a cranial-to-caudal direction, left to right and top to bottom.

of the dermal sinus may be visualized with CT myelography or MR imaging (Fig. 7). ${ }^{48}$

\section{Tight Filum Terminale Syndrome}

The tight filum terminale syndrome refers to the clinical presence of the TCS in a patient with a low-lying conus medullaris, a terminal filum greater than $2 \mathrm{~mm}$ in diameter and no other tethering agents. ${ }^{19,48}$ In $86 \%$ of the patients, the tip of the conus medullaris lies inferior to L-2. ${ }^{13}$ The terminal filum is the tethering agent and these patients respond to sectioning of the terminal filum. ${ }^{69,70}$ The low-lying conus and thickened terminal filum may be visualized on CT or MR imaging. ${ }^{48}$

\section{Terminal Myelocystoceles}

Terminal myelocystoceles represent a rare form of OSD in which elements include an expansion of the central canal of the caudal spinal cord by a cerebrospinal fluidcontaining terminal cyst, which itself is surrounded by an expanded dural sheath. ${ }^{47,58}$ Associated with this is a lipoma. ${ }^{58}$ The inner terminal cyst communicates with the central canal of the spinal cord, whereas the outer dural sac communicates with subarachnoid space. ${ }^{58}$ The outer and inner fluid spaces usually do not communicate. ${ }^{58}$ Tethering results from the attachment of the myelocystocele to the inferior aspect of the spinal cord. ${ }^{49,58}$ Terminal myelocystoceles are associated with multiple congenital defects including cloacal exstrophy, imperforate anus, omphalocele, pelvic deformity, talipes equinovarus, renal abnormalities, and ambiguous genitalia. ${ }^{9}$ Neurosurgical intervention involves separating the spinal cord from the fluid-filled terminal myelocystocele, reconstructing the neural tube, and then incising and reapproximating the dura to recreate the subarachnoid space. ${ }^{9}$ Patients with terminal myelocystoceles typically have no bowel or bladder control and possess poor lower-extremity function. ${ }^{2}$ The

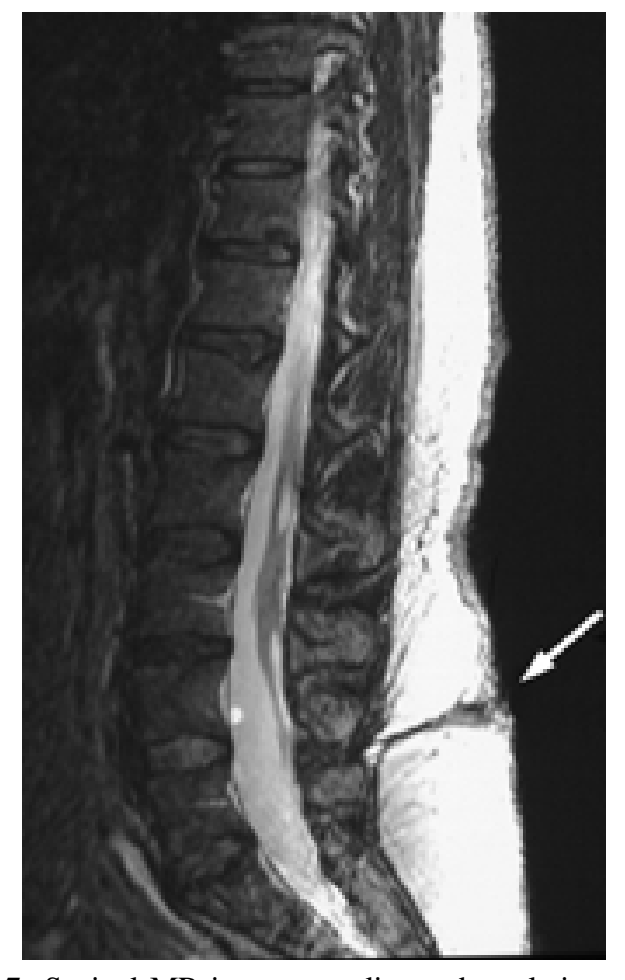

Fig. 7. Sagittal MR image revealing a dermal sinus tract (arrow) that extends from the skin and attaches to the spinal cord.

diagnosis of terminal myelocystocele can be made by performing MR imaging or ultrasonography., 90

\section{Neurenteric Cysts}

Spinal neurenteric cysts are rare congenital malformations lined by alimentary tract mucosa ${ }^{18}$ and are formed by entrapment of endodermal tissue between a split notochord. ${ }^{53}$ The cyst may be extraspinal with mediastinal or abdominal extension, or it may be intramedullary. ${ }^{30}$ Whereas the cyst is frequently associated with anterior or posterior spina bifida, it may be found without any associated dysraphic anomalies. ${ }^{53}$ Patients harboring these lesions may present with progressive signs of spinal cord compression that may be acute. ${ }^{30,53}$ Neurosurgical intervention involves gross-total resection or partial excision of the cyst. In one study, the cyst recurrence rate in patients in whom partial excision was performed was $11 \%$; no recurrence of the lesion occurred in those in whom gross-total resection was performed..$^{53}$ The diagnosis of neurenteric cyst can be made with MR imaging or ultrasonography, and intraoperative ultrasonography may be of value for the intraoperative localization of the lesion. ${ }^{30,53}$

\section{Meningocele Manqué}

Meningocele manqué refers to a dysraphic element of dorsal tethering bands composed of fibrotic or atretic neural tissue connecting the spinal cord to dura or surrounding structures (Fig. 8). ${ }^{42}$ They are usually found incidentally during surgical exploration for other elements of OSD $^{31}$ and may exist distant from the site of obvious tethering. These tethering bands are usually found at the site of diastematomyelia; surgical treatment involves the lysis 
D. E. Warder

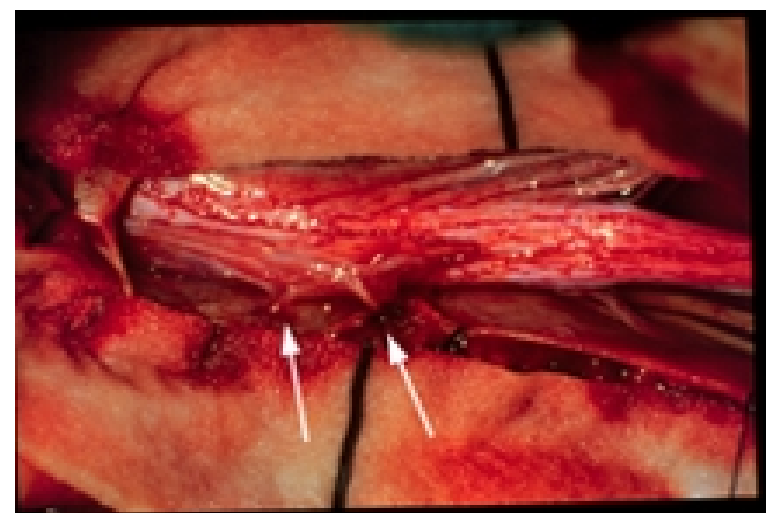

Fig. 8. Intraoperative photograph showing a meningocele manqué. Dorsal tethering bands (arrows) attaching the spinal cord to the dura are displayed.

of the bands. Meningocele manqué may be visualized by MR imaging or CT myelography. ${ }^{31}$

\section{SYNDROMES OF THE TETHERED CORD}

\section{Tethered Cord Syndrome and the Conus in a Normal Position}

In its classic form, TCS implies a low-lying conus medullaris. ${ }^{23,24}$ There is some variation in the definition of an "abnormally" low conus. To some, below the L1-2 disc space is abnormally low ${ }^{51}$ whereas to others, below the inferior aspect of the L-2 vertebral body is abnormally low. ${ }^{57}$ Both definitions refer to Barson's ${ }^{3}$ anatomical measurements. Reimann and Anson ${ }^{62}$ demonstrated in an autopsy study in the normal adult population that the spinal cord terminates at or above the inferior aspect of the L-2 vertebral body in $95 \%$ of the population and that it terminates at or above the L1-2 disc space in $57 \%$ of the population (Fig. 9). The conus medullaris reaches its mature adult level approximately 3 months after full-term gestation. ${ }^{3}$ Tethered cord syndrome may occur in the presence of a conus in the normal position. ${ }^{69,70}$ In patients who present with TCS in the setting of a conus in a normal position, the same frequency of the following is seen: cutaneous stigmata of OSD (46\% compared with 52\%), extremity abnormalities (39\% compared with $32 \%$ ), bone abnormalities (100\% compared with 95\%), dysraphic anomalies (62\% compared with $78 \%)$, and neurological abnormalities (77\% compared with $87 \%$ ) as patients with TCS in the setting of a low-lying conus, respectively. ${ }^{69,70}$ None of the patients studied with TCS in the setting of a conus in a normal position presented with urological dysfunction as the only abnormality ${ }^{70}$ and this patient population appeared to be different from that in whom a tight filum terminale is expressed solely in the presence of a hyperreflexic neurogenic bladder and a conus at a normal level. ${ }^{34,64,65}$

\section{Tethered Cord Syndrome In Adults}

The new onset of TCS in the adult population is an unusual but well-described entity. ${ }^{20,57,61}$ The late onset of presentation may be related to the cumulative effects

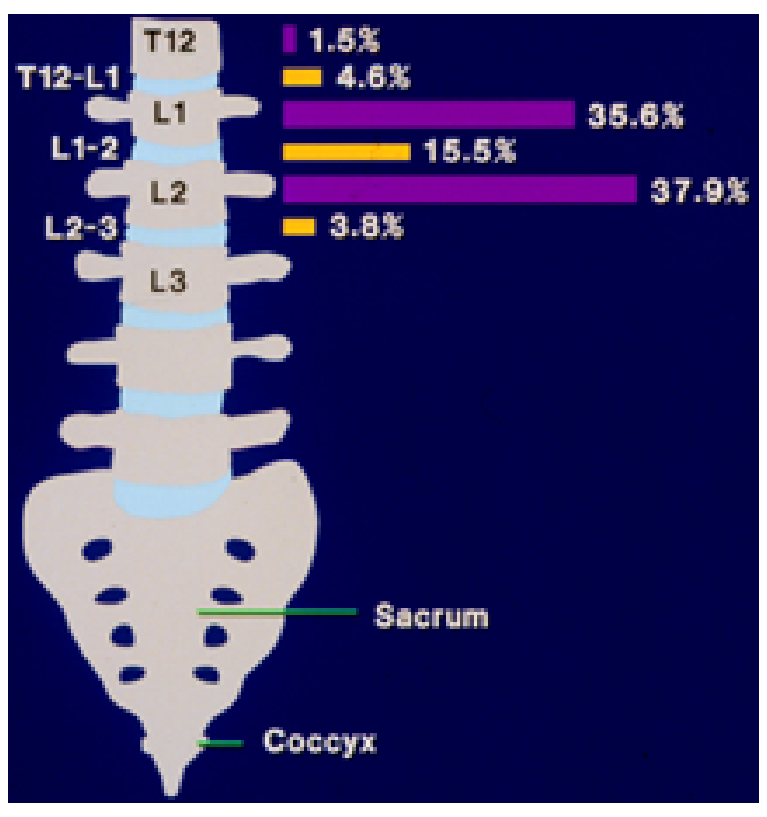

Fig. 9. Representative photograph distribution of the position of the conus medullaris in the normal adult population. The level of termination of the spinal cord in the normal adult population, as determined by Reimann and Anson, in 1944, is displayed.

of repeated microtrauma during flexion and extension. ${ }^{20}$ Some authors have noted distinct precipitating events preceding symptoms in approximately $60 \%$ of the adult patients. ${ }^{57}$ Such precipitating factors include heavy lifting, traumatic injury, and the lithotomy position. ${ }^{57}$ Tethered cord syndrome in the adult population is similar to that in the pediatric population with respect to the incidence of cutaneous stigmata of OSD, neurological abnormalities at presentation, vertebral and orthopedic anomalies, and specific dysraphic elements..$^{20,57}$ In the adult population, however, TCS is accompanied by nondermatomal low-back and leg pain in 50 to $78 \%$ of patients. ${ }^{20,57}$ Surgical untethering in the adult population may relieve pain in $80 \%$ of patients, ${ }^{57}$ and it may improve bowel and bladder dysfunction in $38 \%$ of patients. ${ }^{57}$ Opinions vary regarding the surgical treatment of the asymptomatic adult, particularly the elderly or infirm adult with a tethered cord. Some authors believe that surgical intervention should be offered to all individuals ${ }^{20,47}$ because recovery of lost bowel and bladder function is low. Other authors, however, maintain that only asymptomatic adults who lead physically active lifestyles should be offered surgery. 20,57

\section{The Normal Conus and the Hyperreflexic Neurogenic Bladder}

Urinary incontinence from bladder instability is a common problem for which patients present to a urologist. ${ }^{35}$ Urodynamic studies in the setting of incontinence often reveal detrusor hyperreflexia. ${ }^{38}$ The occurrence of urinary incontinence has two age-related peaks: it occurs in children less than 10 years of age and in adults between 60 and 80 years of age. ${ }^{38}$ There is a wide variety of medical and urological treatments for bladder instability-related urinary incontinence. In the pediatric and young adult 


\section{Tethered cord syndrome and occult spinal dysraphism}

populations, there is an annual spontaneous cure rate for urinary incontinence of 14 to $16 \%$ in each age group up to 19 years of age. ${ }^{15}$

Tethered cord syndrome has been postulated as a cause of the neurogenic hyperreflexic bladder even in the presence of a conus medullaris in a normal position, a normal terminal filum, an otherwise normal neurological status, no elements of OSD, and no orthopedic or vertebral anomalies. ${ }^{34,37,64,65}$ This diagnosis of urinary incontinence in patients with a tethered cord in a normal position is one of exclusion because, by definition, the only abnormality, clinically or radiologically, is urinary incontinence. Another diagnosis of exclusion for urinary incontinence in the pediatric population includes the nonneurogenic neurogenic bladder. ${ }^{28}$

Several studies have included patients with a neurogenic bladder in whom the authors documented detrusor hyperreflexia, a conus in a normal position, but no elements of OSD, and no orthopedic, vertebral, or neurological anomalies. ${ }^{34,36,37,65}$ These patients underwent division of the terminal filum. Table 1 summarizes data regarding the presentation and outcome of the patients in these studies. Kondo, et al., ${ }^{36}$ presented 27 patients treated over a 5 -year period, who had a tight filum and a conus in a normal position. In five patients there were also cutaneous stigmata of OSD. All 27 patients underwent sectioning of the filum. Only $27 \%$ of the patients experienced improved bladder function as determined by urodynamic testing at the 6-month follow-up visit, whereas $44 \%$ experienced improvement at 26 months. The increase in improvement over time was believed to have resulted from a spontaneous cure rather than from the untethering of the spinal cord. The authors concluded that, although a tight filum might be the cause of intractable urinary incontinence, resection of the filum was not recommended because of the low success rate. ${ }^{36}$

In a more recent study, Selçuki, et al., ${ }^{65}$ described a group of 17 patients treated over 6 years who had urinary incontinence with documented detrusor hyperreflexia and a conus in a normal position. In one patient, there were independent anomalies associated with OSD. All patients

TABLE 1

Summary of studies proposing a neurogenic hyperreflexic bladder resulting from a tethered spinal cord with a conus medullaris in a normal position

\begin{tabular}{|c|c|c|c|}
\hline Articles & $\begin{array}{l}\text { No. of } \\
\text { Patients } \\
\text { (yrs to ac- } \\
\text { cumulate } \\
\text { patients) }\end{array}$ & $\begin{array}{l}\text { Percentage } \\
\text { of Patients } \\
\text { W/ Other In- } \\
\text { dependent Ele- } \\
\text { ments of OSD }\end{array}$ & $\begin{array}{l}\text { Urodynamic } \\
\text { Evidence of } \\
\text { Improvement* }\end{array}$ \\
\hline $\begin{array}{l}\text { Kondo, et al., } \\
1986\end{array}$ & 15 (14) & 87 & $\begin{array}{l}\text { improvement in } 67 \% \\
\text { at } 20 \mathrm{mos}\end{array}$ \\
\hline $\begin{array}{l}\text { Kondo, et al., } \\
1988\end{array}$ & 27 (5) & 19 & $\begin{array}{l}\text { improvement in } 27 \% \\
\text { at } 6 \mathrm{mos} \text {; improvement } \\
\text { in } 44 \% \text { at } 26 \mathrm{mos}\end{array}$ \\
\hline $\begin{array}{l}\text { Khoury, et al., } \\
1990\end{array}$ & $31(3)$ & 52 & $\begin{array}{l}\text { improvement in } 59 \% \\
\text { at } 13 \text { mos }\end{array}$ \\
\hline $\begin{array}{l}\text { Selçuki, et al., } \\
2000\end{array}$ & 17 (6) & 6 & $\begin{array}{l}\text { improvement in } 96 \% \\
\text { immediately; improve- } \\
\text { ment in } 58 \% \text { at } 1 \text { mo }\end{array}$ \\
\hline
\end{tabular}

* Demonstrated after sectioning of the terminal filum. underwent sectioning of the filum. Immediately following surgery, $96 \%$ of the patients noted improved bladder function, whereas at 1 month postoperatively $58 \%$ had improved function, as determined by urodynamic testing. ${ }^{65}$ The authors concluded that surgical untethering of the conus medullaris in a normal position should not be the sole treatment for incontinence from bladder hyperreflexia, although it was an effective treatment.

\section{SUMMARY OF ISSUES}

The diagnosis of TCS is most easily made in the setting of clinical findings that are supplemented with neuroimaging studies. Clinical evidence of OSD including skin changes, orthopedic anomalies, vertebral anomalies, and associated anorectal malformations may suggest a tethered spinal cord. Progressive neurological/urological dysfunction localized to the conus medullaris may also suggest a tethered cord. Ultrasonography, CT scanning, MR imaging, and plain radiography assist with the localization of the level of the conus medullaris and the identification of the specific tethering agent. A patient's preoperative neurological and urological status may be further investigated by using electromyography, cystometrography, and evoked potential monitoring.

Surgical intervention for the tethered spinal cord involves the intraoperative identification of the tethering lesions, release of the spinal cord, and reconstruction to as normal anatomy as possible. The carbon dioxide laser has been found to be useful for debulking and dissecting tethering lesions and reducing blood loss. Intraoperative electromyography or evoked potentials may also be used. Surgery-related complications include the standard anesthesia-related risks, neurological worsening, cerebrospinal fluid leakage, and meningitis. ${ }^{48,61}$

The goal of untethering of the spinal cord is to stabilize neurological function. The presenting symptoms of motor weakness, sensory dysfunction, bladder dysfunction, and pain improve to different degrees following treatment depending on the different dysraphic lesions. Improvement of motor weakness occurs in 12 to $60 \%, 8,39$ sensory dysfunction improvement in 40 to $60 \%,{ }^{8,70}$ pain symptom improvement in 50 to $88 \%,,^{20,70}$ and bladder dysfunction improvement in 19 to $67 \%{ }^{14,37,39}$ of patients undergoing spinal cord untethering. In the majority of patients who undergo untethering of the spinal cord either improvement or no deterioration of neurological status is demonstrated at long-term follow up. $2,39,48,66,70$

In patients who have previously undergone untethering procedures, a progressive neurological deterioration may signal retethering, which may occur in up to $15 \%$ of patients depending on the specific tethering lesion. ${ }^{33}$ Longterm neurological and urological follow-up study can aid with the identification of patients with retethering of the spinal cord who do respond to reoperation for untethering. ${ }^{48}$

Current controversies with respect to the TCS include: 1) the untethering of the spinal cord in asymptomatic patients; and 2) the proposed neurogenic hyperreflexic bladder resulting from a tethered spinal cord with a conus medullaris in a normal position.

The many different tethering lesions of the TCS and the 
unknown natural history of many of these lesions have led a few authors to propose the conservative management of some asymptomatic patients. ${ }^{10,11,74}$ However, because early intervention is an effective prophylaxis against progressive neurological decline, which may occur precipitously, and because full recovery of neurological function after a decline is not certain, the majority of authors recommend an untethering procedure for the asymptomatic patient with a tethered spinal cord. ${ }^{20,33,39,48,61,67}$

The development of a neurogenic hyperreflexic bladder from a tethered spinal cord with a conus in a normal position and an otherwise normal status is a diagnosis of exclusion and has been postulated; $;^{34,64,65}$ sectioning of the filum for this has been performed with varying results (Table 1). ${ }^{34,36,37,65}$ Different results have led some authors not to recommend sectioning of the filum in this setting because of the poor success rate, ${ }^{36}$ whereas others concluded that this was an effective treatment. ${ }^{65}$ The interpretation of the response rate of the neurogenic hyperreflexic bladder to the sectioning of the filum is somewhat obscured by the spontaneous rate of cure for this condition. Because of the high prevalence of the neurogenic bladder of the hyperreflexic type, and the high spontaneous cure rate for this disorder, better controlled studies may provide important data regarding the efficacy of this proposed treatment.

\section{References}

1. Ammerman BJ, Henry JM, De Girolami U, et al: Intradural lipomas of the spinal cord. A clinicopathological correlation. J Neurosurg 44:331-336, 1976

2. Andar UB, Harkness WFJ, Hayward RD: Split cord malformations of the lumbar region. A model for the neurosurgical management of all types of 'occult' spinal dysraphism? Pediatr Neurosurg 26:17-24, 1997

3. Barson AJ: The vertebral level of termination of the spinal cord during normal and abnormal development. J Anat 106: 489-497, 1970

4. Boone D, Parsons D, Lachmann SM, et al: Spina bifida occulta: lesion or anomaly? Clin Radiol 36:159-161, 1985

5. Brickner WM: Spina bifida occulta. Am J Med Sci 155:474, 1918

6. Brown E, Matthes JC, Bazan C, et al: Prevalence of incidental intraspinal lipoma of the lumbosacral spine as determined by MRI. Spine 19:833-836, 1994

7. Byrne RW, Hayes EA, George TM, et al: Operative resection of 100 spinal lipomas in infants less than 1 year of age. Pediatr Neurosurg 23:182-187, 1995

8. Caruso R, Cervoni L, Fiorenza F, et al: Occult dysraphism in adulthood. A series of 24 cases. J Neurosurg Sci 40:221-225, 1996

9. Choi SH, McComb JG: Long-term outcome of terminal myelocystocele patients. Pediatr Neurosurg 32:86-91, 2000

10. Cornette L, Verpoorten C, Casaer P: Concerning the article by Andar UB et al. Pediatr Neurosurg 26:17-24, 1997: Upper and lower motor neuron dysfunction in closed spinal dysraphism. Pediatr Neurosurg 29:222-223, 1998 (Letter)

11. Cornette L, Verpoorten C, Lagae L, et al: Tethered cord syndrome in occult spinal dysraphism: timing and outcome of surgical release. Neurology 50:1761-1765, 1998

12. Davidoff AM, Thompson CV, Grimm JM, et al: Occult spinal dysraphism in patients with anal agenesis. J Pediatr Surg 26: 1001-1005, 1991

13. Fitz CR, Harwood-Nash DC: The tethered conus. AJR 125: 515,1975
14. Fone PD, Vapnek JM, Litwiller SE, et al: Urodynamic findings in the tethered spinal cord syndrome: does surgical release improve bladder function? J Urol 157:604-609, 1997

15. Forsythe WI, Redmond A: Enuresis and spontaneous cure rate. Study of 1129 eneuretics. Arch Dis Child 49:259-263, 1974

16. French BN: The embryology of spinal dysraphism. Clin Neurosurg 30:295-340, 1983

17. French BN: Midlline fusion defects and defects of formation, in Youmans JR (ed): Neurological Surgery. Philadelphia: WB Saunders, 1982, Vol 3, pp 1236-1380

18. Friede RL (ed): Developmental Neuropathology. New York: Springer-Verlag, 1989, pp 292-293

19. Garceau GJ: Filum terminale syndrome (contraction syndrome). J Bone Joint Surg 35 (Am):711-716, 1953

20. Gupta SK, Khosla VK, Sharma BS, et al: Tethered cord syndrome in adults. Surg Neurol 52:362-370, 1999

21. Guthkelch AN: Diastematomyelia with median septum. Brain 97:729-742, 1974

22. Hansasuta A, Tubbs RS, Oakes WJ: Filum terminale fusion and dural sac termination: study in 27 cadavers. Pediatr Neurosurg 30:176-179, 1999

23. Hendrick EB, Hoffman H, Humphreys RP: The tethered spinal cord. Clin Neurosurg 30:457-463, 1983

24. Hoffman HJ, Hendrick EB, Humphreys RP: The tethered spinal cord: its protean manifestations, diagnosis and surgical correction. Childs Brain 2:145-155, 1976

25. Hoffman HJ, Taecholarn C, Hendrick EB, et al: Management of lipomyelomeningoceles. Experience at the Hospital for Sick Children, Toronto. J Neurosurg 62:1-8, 1985

26. James CC, Lassman LP: Diastematomyelia and the tight filum terminale. J Neurol Sci 10:193-196, 1970

27. James CC, Lassman LP: Spinal dysraphism. Spinal cord lesions associated with spina bifida occulta. Physiotherapy 48: 154-157, 1962

28. Jayanthi VR, Khoury AE, McLorie GA, et al: The nonneurogenic neurogenic bladder of early infancy. J Urol 158: 1281-1285, 1997

29. Jones: Spina bifida occulta: no paralytic symptoms until seventeen years of age; spine trephined to relieve pressure on the cauda equina; recovery. Reports on the medical and surgical practice in the hospitals and asylums of Great Britain, Ireland and the Colonies. Br Med J 1:173-174, 1891

30. Kadhim H, Proaño PG, Martin CS, et al: Spinal neurenteric cyst presenting in infancy with chronic fever and acute myelopathy. Neurology 54:2011-2015, 2000

31. Kaffenberger DA, Heinz ER, Oakes WJ, et al: Meningocele manqué: radiologic findings with clinical correlation. AJNR 13:1083-1088, 1992

32. Kanev PM, Lemire RJ, Loeser JD, et al: Management and longterm follow-up review of children with lipomyelomeningocele, 1952-1987. J Neurosurg 73:48-52, 1990

33. Kanev PM, Nierbrauer KS: Reflections on the natural history of lipomyelomeningocele. Pediatr Neurosurg 22:137-140, 1995

34. Khoury AE, Hendrick EB, McLorie GA, et al: Occult spinal dysraphism: clinical and urodynamic outcome after division of the filum terminale. J Urol 144:426-429, 1990

35. Kondo A: Cystourethrograms characteristic of bladder instability in children. Urology 35:242-246, 1990

36. Kondo A, Gotoh M, Kato K, et al: Treatment of persistent enuresis: results of severing a tight filum terminale. Br J Urol 62: $42-45,1988$

37. Kondo A, Kato K, Kanai S, et al: Bladder dysfunction secondary to tethered cord syndrome in adults: is it curable? J Urol 135:313-316, 1986

38. Kondo A, Kobayashi M, Otani T, et al: Children with unstable bladder: clinical and urodynamic observation. J Urol 129: 88-91, 1983

39. Koyanagi I, Iwasaki Y, Hida K, et al: Surgical treatment sup- 
posed natural history of the tethered cord with occult spinal dysraphism. Childs Nerv Syst 13:268-274, 1997

40. Kriss VM, Desai NS: Occult spinal dysraphism in neonates: assessment of high-risk cutaneous stigmata on sonography. AJR 171:1687-1692, 1998

41. Lassman LP, James CC: Lumbosacral lipomas: critical survey of 26 cases submitted to laminectomy. J Neurol Neurosurg Psychiatry 30:174-181, 1967

42. Lassman LP, James CC: Meningocele manqué. Childs Brain 3:1-11, 1977

43. Lemire, RJ, Siebert JR: Neuroembryology, in Wilkins RH, Rengachary SS (eds): Neurosurgery Update II. New York: McGraw-Hill, 1991, pp 286-291

44. Lichtenstein BW: Distant neuroanatomic complications of spina bifida (spinal dysraphism): hydrocephalus, Arnold-Chiari I deformity, stenosis of aqueduct of Sylvius, etc. Pathogenesis and pathology. Arch Neurol Psychiatry 47:195-214, 1942

45. Lichtenstein BW: Spinal dysraphism, spina bifida and myelodysplasia. Arch Neurol Psychiatry 44:792-807, 1940

46. McLendon RE, Oakes WJ, Heinz ER, et al: Adipose tissue in the filum terminale: a computed tomographic finding that may indicate tethering of the spinal cord. Neurosurgery 22: 873-876, 1988

47. McLone DG: The adult with a tethered cord. Clin Neurosurg 43:203-209, 1996

48. McLone DG: Occult dysraphism and the tethered spinal cord lipomas in Choix M, Di Rocco C, Hockley A, et al (eds): Pediatric Neurosurgery. Philadelphia: Churchill Livingstone, 1999, pp 61-78

49. McLone DG, Naidich TP: Terminal myelocystocele. Neurosurgery 16:36-43, 1985

50. Meyer SH, Morris GF, Pretorius DH, et al: Terminal myelocystocele: important differential diagnosis in the prenatal assessment of spina bifida. J Ultrasound Med 17:193-197, 1998

51. Naidich TP, McLone DG: Ultrasonography versus computed tomography, in Holtzman RN, Stein BM (eds): The Tethered Spinal Cord. New York: Thieme-Stratton, 1985, pp 47-58

52. Oakes WJ: Management of spinal cord lipomas and lipomyelomeningoceles: newer concepts , in Wilkins RH, Rengachary SS (eds): Neurosurgery Update II. New York: McGraw-Hill, 1991, pp 345-352

53. Paleologos TS, Thom M, Thoms DG: Spinal neurenteric cysts without associated malformations. Are they the same as those presenting in spinal dysraphism? Br J Neurosurg 14:185-194, 2000

54. Pang D: Split cord malformation: Part 2: clinical syndrome. Neurosurgery 31:480-500, 1992

55. Pang D: Tethered cord syndrome: newer concepts, in Wilkins RH, Rengachary SS (eds): Neurosurgery Update II. New York: McGraw-Hill, 1991, pp 336-344

56. Pang D, Dias MS, Ahab-Barmada M: Split cord malformation. Part I: a united theory of embryogenesis for double spinal cord malformations. Neurosurgery 31:451-480, 1992

57. Pang D, Wilberger JE Jr: Tethered cord syndrome in adults. J Neurosurg 57:32-47, 1982
58. Peacock WJ, Murovic JA: Magnetic resonance imaging in myelocystoceles. Report of two cases. J Neurosurg 70:804-807, 1989

59. Perret G: Diagnosis and treatment of diastematomyelia. Surg Gynecol Obstet 105:69-83, 1957

60. Pierre-Kahn A, Lacombe J, Pichon J, et al: Intraspinal lipomas with spina bifida. Prognosis and treatment in 73 cases. J Neurosurg 65:756-761, 1986

61. Ratliff JR, Mahoney PS, Kline DG: Tethered cord syndrome in adults. South Med J 92:1199-1203, 1999

62. Reimann AF, Anson BJ: Vertebral level of termination of the spinal cord with a report of a case of sacral cord. Anat Rec 88: 127-138, 1944

63. Schneider SJ, Rosenthal AD, Greenberg BM, et al: A preliminary report on the use of laser-Doppler flowmetry during tethered cord release. Neurosurgery 32:214-217, 1993

64. Selçuki M, Coskun K: Management of tight filum terminale syndrome with special emphasis on normal level conus medullaris (NLCM). Surg Neurol 50:318-322, 1998

65. Selçuki M, Ünlü A, Ugur HC, et al: Patients with urinary incontinence often benefit from surgical detethering of tight filum terminale. Childs Nerv Syst 16:150-155, 2000

66. Sharif S, Allcutt D, Marks C, et al: "Tethered cord syndrome" -recent clinical experience. Br J Neurosurg 11:49-51, 1997

67. Soonawala N, Overweg-Plandsoen WC, Brouwer OF: Early clinical signs and symptoms in occult spinal dysraphism: a retrospective case study of 47 patients. Clin Neurol Neurosurg 101:11-14, 1999

68. Streeter GL: Factors involved in the formation of the filum terminale. Am J Anat 25:1-12, 1919

69. Warder DE, Oakes WJ: Tethered cord syndrome and the conus in a normal position. Neurosurgery 33:374-378, 1993

70. Warder DE, Oakes WJ: Tethered cord syndrome: the low-lying and normally positioned conus. Neurosurgery 34:597-600, 1994

71. Warf BC, Scott RM, Barnes PD, et al: Tethered spinal cord in patients with anorectal and urogenital malformations. Pediatr Neurosurg 19:25-30, 1993

72. Uchino A, Mori T, Ohno M: Thickened fatty filum terminale: MR imaging. Neuroradiology 33:331-333, 1991

73. Yamada S, Zinke DE, Sanders D: Pathophysiology of "tethered cord syndrome.” J Neurosurg 54:494-503, 1981

74. Zerah M, Pierre-Kahn A, Catala M: Lumbosacral lipomas in Choix M, Di Rocco C, Hockley A, Wet al (eds): Pediatric Neurosurgery. Philadelphia: Churchill Livingstone, 1999, pp 79-100

Manuscript received December 4, 2000.

Accepted in final form December 21, 2000.

Address reprint requests to: Daryl E. Warder, M.D., Ph. D., Division of Neurosurgery, Room 9.208, John Sealy Annex, 301 University Boulevard, Galveston, TX 77555-0517. email: dwarder@ utmb.edu. 